\title{
Article \\ Cerebral Expression of Metabotropic Glutamate Receptor Subtype 5 in Idiopathic Autism Spectrum Disorder and Fragile $X$ Syndrome: A Pilot Study
}

\author{
James Robert Brašić 1,*(D), Ayon Nandi ${ }^{1}$, David S. Russell 2,3 ${ }^{\mathbb{D}}$, Danna Jennings ${ }^{2,3,4}$, Olivier Barret ${ }^{2,3,5}$, \\ Samuel D. Martin 1,6, Keith Slifer 7,8, Thomas Sedlak ${ }^{1,9}$, John P. Seibyl 2,3, Dean F. Wong ${ }^{1,10(D)}$ and \\ Dejan B. Budimirovic $7,11, *$ (D)
}

\section{check for} updates

Citation: Brašić, J.R.; Nandi, A.; Russell, D.S.; Jennings, D.; Barret, O.; Martin, S.D.; Slifer, K.; Sedlak, T.; Seibyl, J.P.; Wong, D.F.; et al. Cerebral Expression of Metabotropic Glutamate Receptor Subtype 5 in Idiopathic Autism Spectrum Disorder and Fragile X Syndrome: A Pilot Study. Int. J. Mol. Sci. 2021, 22, 2863. https://doi.org/10.3390/ijms22062863

Academic Editor: Kunio Yui

Received: 31 January 2021

Accepted: 4 March 2021

Published: 11 March 2021

Publisher's Note: MDPI stays neutral with regard to jurisdictional claims in published maps and institutional affiliations.

Copyright: (c) 2021 by the authors. Licensee MDPI, Basel, Switzerland. This article is an open access article distributed under the terms and conditions of the Creative Commons Attribution (CC BY) license (https:/ / creativecommons.org/licenses/by/ $4.0 /)$.
1 Section of High Resolution Brain Positron Emission Tomography Imaging, Division of Nuclear Medicine and Molecular Imaging, The Russell H. Morgan Department of Radiology and Radiological Science, The Johns Hopkins University School of Medicine, Baltimore, MD 21287, USA; anandi1@jh.edu (A.N.); smart149@jhu.edu (S.D.M.); tsedlak@jhmi.edu (T.S.); dfwong@wustl.edu (D.F.W.)

2 Institute for Neurodegenerative Disorders, New Haven, CT 06510, USA; drussell@invicro.com (D.S.R.); Jennings@dnli.com (D.J.); olivier.barret@cea.fr (O.B.); jseibyl@invicro.com (J.P.S.)

3 Research Clinic, Invicro, New Haven, CT 06510, USA

4 Denali Therapeutics, Inc., South San Francisco, CA 94080, USA

5 Laboratoire des Maladies Neurodégénératives, Molecular Imaging Research Center (MIRCen), Institut de Biologie François Jacob, Centre National de la Recherche Scientifique (CNRS), Commissariat à l'Énergie Atomique et aux Énergies Alternatives (CEA), Université Paris-Saclay, 92265 Fontenay-aux-Roses CEDEX, France

6 Department of Neuroscience, Zanvyl Krieger School of Arts and Sciences, The Johns Hopkins University, Baltimore, MD 21218, USA

7 Department of Psychiatry and Behavioral Sciences-Child Psychiatry, The Johns Hopkins University School of Medicine, Baltimore, MD 21205, USA; slifer@kennedykrieger.org

8 Department of Behavioral Psychology, Kennedy Krieger Institute, Baltimore, MD 21205, USA

9 Department of Psychiatry and Behavioral Sciences-General Psychiatry, The Johns Hopkins University School of Medicine, Baltimore, MD 21205, USA

10 Laboratory of Central Nervous System (CNS) Neuropsychopharmacology and Multimodal Imaging (CNAMI), Mallinckrodt Institute of Radiology, Washington University, Saint Louis, MO 63110, USA

11 Department of Psychiatry, Kennedy Krieger Institute, Baltimore, MD 21205, USA

* Correspondence: jbrasic1@jh.edu (J.R.B.); budimirovic@kennedykrieger.org (D.B.B.); Tel.: +1-410-986-0341 (J.R.B.); +1-443-923-2634 (D.B.B.)

Abstract: Multiple lines of evidence suggest that dysfunction of the metabotropic glutamate receptor subtype $5\left(\mathrm{mGluR}_{5}\right)$ plays a role in the pathogenesis of autism spectrum disorder (ASD). Yet animal and human investigations of $\mathrm{mGluR}_{5}$ expression provide conflicting findings about the nature of dysregulation of cerebral mGluR $_{5}$ pathways in subtypes of ASD. The demonstration of reduced mGluR $_{5}$ expression throughout the living brains of men with fragile $X$ syndrome (FXS), the most common known single-gene cause of ASD, provides a clue to examine mGluR $\mathrm{R}_{5}$ expression in ASD. We aimed to (A) compare and contrast mGluR $_{5}$ expression in idiopathic autism spectrum disorder (IASD), FXS, and typical development (TD) and (B) show the value of positron emission tomography (PET) for the application of precision medicine for the diagnosis and treatment of individuals with IASD, FXS, and related conditions. Two teams of investigators independently administered 3- $\left[{ }^{18} \mathrm{~F}\right]$ fluoro-5-(2-pyridinylethynyl)benzonitrile ([$\left.\left.{ }^{18} \mathrm{~F}\right] \mathrm{FPEB}\right)$, a novel, specific mGluR ${ }_{5} \mathrm{PET}_{\text {ligand }}$ to quantitatively measure the density and the distribution of $\mathrm{mGluR}_{5} \mathrm{~s}$ in the brain regions, to participants of both sexes with IASD and TD and men with FXS. In contrast to participants with $\mathrm{TD}, \mathrm{mGluR}_{5}$ expression was significantly increased in the cortical regions of participants with IASD and significantly reduced in all regions of men with FXS. These results suggest the feasibility of this protocol as a valuable tool to measure mGluR $_{5}$ expression in clinical trials of individuals with IASD and FXS and related conditions. 
Keywords: binding potential; cortex; caudate nucleus; cingulate; fragile $\mathrm{X}$ mental retardation 1 gene (FMR1); neurodevelopmental disorders; positron emission tomography (PET); putamen; radiotracer; thalamus

\section{Introduction}

Autism spectrum disorder (ASD) [1] comprises a heterogeneous group of neurodevelopmental disorders including (A) a subtype characterized by a behavioral phenotype with no known etiology [idiopathic autism spectrum disorder (IASD)] [2] and (B) medical disorders with known genetic etiologies [3], such as fragile X syndrome (FXS) [4]. All subtypes of ASD are characterized by impaired social communication and repetitive and restricted behaviors and interests [1-5]. Additionally, FXS and some other subtypes of ASD are also characterized by intellectual disability (ID) [6]. Dysfunction of protein synthesis mediated by abnormal pathways including metabotropic glutamate receptors (mGluR) plays a role in the pathometabolism of IASD [7,8] and FXS [9-12]. Despite the evidence for dysfunction of mGluR ${ }_{5}$ expression in IASD, conflicting findings include the decreased expression in the dorsolateral prefrontal cortex [13] and increased expression in the post-central gyrus and the cerebellum [14].

The confusion about mGluR $_{5}$ expression in IASD may be resolved utilizing techniques that have provided convergent validity to studies of GGluR $_{5}$ expression in FXS, the most common single-gene cause of ASD and ID. FXS results from the presence of the fragile $\mathrm{X}$ mental retardation 1 (FMR1) gene leading to deficits of Fragile X Mental Retardation Protein (FMRP). Dysregulated activation of group I metabotropic glutamate receptors [metabotropic glutamate receptors subtypes 1 and $5\left(\mathrm{mGluR}_{1 / 5}\right)$ ] causing metabotropic glutamate receptor dependent long-term depression (mGluR-LTD) plays a role in the pathogenesis of FXS $[15,16]$. The mechanisms of $\mathrm{mGluR}_{1 / 5}$ dysregulation leading to the neurobehavioral symptoms of FXS have been elucidated by the study of fmr 1 knockout (KO) mouse models. The deficits of FMRP in fmr1 KO mouse models result in dysfunction of crucial group 1 metabotropic glutamatergic pathways leading to dysregulated downstream signaling cascades including the mammalian target of rapamycin (mTOR) and the mitogenactivated protein kinase (MAPK) extracellular signal-regulated kinase (ERK) pathways [17]. The correction of mGluR-LTD and behavioral symptoms in fmr $1 \mathrm{KO}$ mouse models suggests that the a biomarker to measure mGluR $_{5}$ expression in the living human brain represents a means to apply precision molecular medicine to ameliorate behavioral symptoms of FXS and possibly other subtypes of ASD [9,10,17-24].

Clinical trials of FXS have been flawed by several limitations, including the absence of a tool to measure the expression of $\mathrm{mGluR}_{5}$ in the living brains of participants with FXS $[9,12,17,24]$. We showed that $3-\left[{ }^{18} \mathrm{~F}\right]$ fluoro-5-(2-pyridinylethynyl)benzonitrile $\left(\left[{ }^{18} \mathrm{~F}\right] \mathrm{FPEB}\right)$, a novel, specific $\mathrm{mGluR}_{5}$ ligand to quantitatively measure the density and distribution of $\mathrm{mGluR}_{5} \mathrm{~s}$ in the brain regions of humans through PET (Figure 1) [25] may be a promising means to obtain quantitative measurements of $\mathrm{mGluR}_{5}$ expression in individuals with IASD or FXS for clinical trials and other investigations $[14,17,23,26]$. We seek to expand our investigations to compare and contrast $\mathrm{mGluR}_{5}$ expression for participants of both sexes with IASD $[14,23]$ and typical development (TD) and men with FXS $[17,24,26]$. 


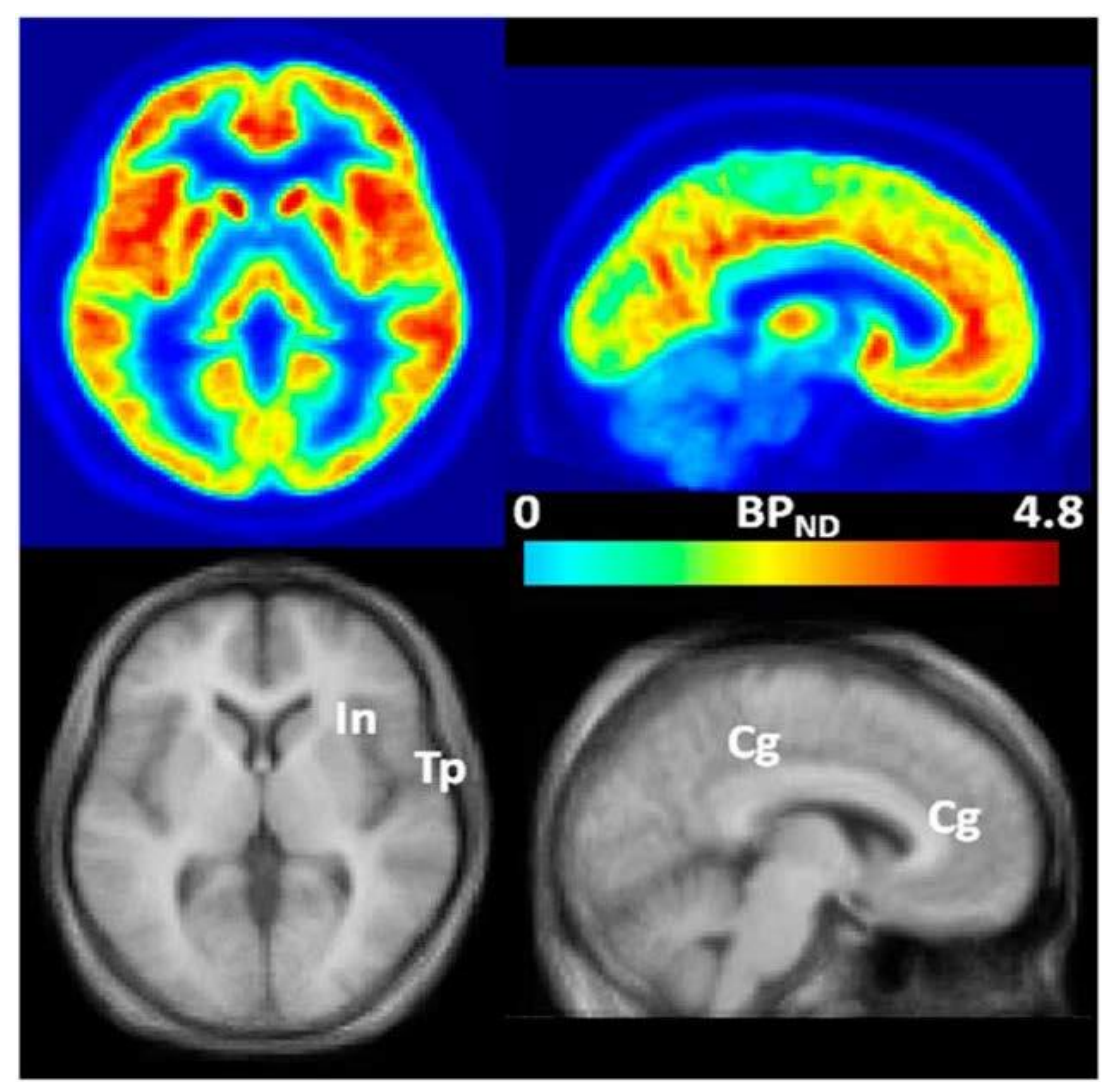

(A)

(B)

Figure 1. Transaxial (A) and sagittal (B) non-displaceable binding potential ( $\left.\mathrm{BP}_{\mathrm{ND}}\right)$ [27] images of 3- $\left[{ }^{18}\right.$ F]fluoro-5-(2-pyridinylethynyl)benzonitrile ([$\left.\left.{ }^{18} \mathrm{~F}\right] \mathrm{FPEB}\right)$ (top) and matching magnetic resonance (MR) images (bottom) in statistical parametric mapping (SPM) [25] standard space. Regions with high $\mathrm{BP}_{\mathrm{ND}}$ values, name.ly insular $(\mathrm{In})$, temporal $(\mathrm{Tp})$, and cingulate $(\mathrm{Cg})$ cortices, are indicated on co-registered MRimages [25]. This research was originally published in JNM. Wong DF, Waterhouse R, Kuwabara H, Kim J, Brašić JR, Chamroonrat W, Stabins M, Holt DP, Dannals RF, Hamill TG, Mozley PD. ${ }^{18}$ F-FPEB, a PET radiopharmaceutical for quantifying metabotropic glutamate 5 receptors: a first-in-human study of radiochemical safety, biokinetics, and radiation dosimetry. J Nucl Med. 2013;54:388-396. (c) SNMMI [25].

Development of interventions to ameliorate the specific molecular deficits of individuals with IASD and FXS with and without ASD will facilitate the utilization of precision medicine to target the unique needs of each person $[9,24]$.

We aimed to (A) compare and contrast $\mathrm{mGlu}_{5}$ expression for participants of both sexes with IASD [14,23] and typical development (TD) [14,25] and men with FXS [17,26] and (B) show the value of PET with $\left(\left[{ }^{18} \mathrm{~F}\right] \mathrm{FPEB}\right)$ for the application of precision medicine for the diagnosis and treatment of individuals with IASD, FXS, and related conditions $[9,17,24,28]$.

\section{Results}

The clinical characteristics of all participants \{group (IASD, FXS, or TD), institution [Institute for Neurodegenerative Disorders (IND) or Johns Hopkins University (JHU)], sex (female or male), age in years, and basal metabolic index (BMI)\} are tabulated in Table $1[26,29]$. 
Table 1. Clinical characteristics of participants [26,29].

\begin{tabular}{|c|c|c|c|c|c|}
\hline Participant & Group & Institution & Sex & Age in Years & BMI \\
\hline INDTD01 & TD & IND & Male & 44 & . \\
\hline INDTD02 & TD & IND & Male & 57 & . \\
\hline INDTD07 & TD & IND & Female & 62 & . \\
\hline INDTD08 & TD & IND & Female & 62 & . \\
\hline INDTD14 & TD & IND & Male & 28 & 25.8 \\
\hline INDTD16 & $\mathrm{TD}$ & IND & Male & 31 & 29.8 \\
\hline INDTD17 & TD & IND & Male & 38 & 25.0 \\
\hline INDTD30 & $\mathrm{TD}$ & IND & Female & 28 & . \\
\hline INDTD35 & TD & IND & Female & 56 & 42.3 \\
\hline INDTD47 & TD & IND & Female & 22 & . \\
\hline INDTD48 & TD & IND & Female & 29 & . \\
\hline INDTD49 & $\mathrm{TD}$ & IND & Female & 20 & . \\
\hline JHUTD4 & $\mathrm{TD}$ & JHU & Female & 19 & 28.4 \\
\hline JHUTD6 & $\mathrm{TD}$ & JHU & Female & 19 & . \\
\hline JHUTD14 & TD & JHU & Male & 24 & 21.7 \\
\hline JHUTD105 & TD & JHU & Male & 26 & . \\
\hline JHUTD1001 & TD & JHU & Male & 32 & 27.1 \\
\hline JHUTD1002 & TD & JHU & Male & 27 & 28.6 \\
\hline JHUTD1005 & TD & JHU & Male & 39 & 29.3 \\
\hline JHUASD3 & IASD & JHU & Male & 18 & 28.8 \\
\hline JHUASD4 & IASD & JHU & Male & 18 & . \\
\hline JHUASD5 & IASD & JHU & Male & 19 & 22.2 \\
\hline JHUASD7 & IASD & JHU & Female & 18 & 22.3 \\
\hline JHUASD8 & IASD & JHU & Male & 23 & 28.5 \\
\hline JHUASD9 & IASD & JHU & Male & 20 & 19.4 \\
\hline JHUASD12 & IASD & JHU & Male & 22 & 20.7 \\
\hline INDFXS34 & FXS & IND & Male & 23 & 36.6 \\
\hline INDFXS38 & FXS & IND & Male & 24 & 30.9 \\
\hline INDFXS40 & FXS & IND & Male & 22 & 33.2 \\
\hline INDFXS41 & FXS & IND & Male & 27 & 25.8 \\
\hline INDFXS42 & FXS & IND & Male & 34 & . \\
\hline INDFXS44 & FXS & IND & Male & 26 & 24.1 \\
\hline INDFXS45 & FXS & IND & Male & 33 & 22.0 \\
\hline INDFXS-M50 & FXS & IND & Male & 57 & 34.1 \\
\hline JHUFXS2 & FXS & JHU & Male & 24 & 34.9 \\
\hline JHUFXS4 & FXS & $\mathrm{JHU}$ & Male & 27 & 28.3 \\
\hline
\end{tabular}

BMI: Basal metabolic index; FXS: Fragile X syndrome; IASD: idiopathic autism spectrum disorder; IND: Institute for Neurodegenerative Disorders; JHU: Johns Hopkins University; TD: Typical development; (Period): Missing data.

The $m_{G l u R_{5}}$ uptake of participants in the regions of interest (ROI) [caudate nucleus $(\mathrm{CN})$, medial temporal cortex (mTp), occipital cortex $(\mathrm{Oc})$, parietal cortex $(\mathrm{Pa})$, posterior cingulate cortex $(\mathrm{pCg})$, putamen $(\mathrm{Pu})$, thalamus $(\mathrm{Th})$, and temporal lobe $(\mathrm{Tp})]$ of all participants are recorded in Table $2[26,29]$. 
Table 2. Metabotropic glutamate receptor subtype 5 uptake in regions of interest of participants [26,29].

\begin{tabular}{|c|c|c|c|c|c|c|c|c|}
\hline Participant & $\mathrm{CN}$ & $\mathrm{mTp}$ & Oc & $\mathbf{P a}$ & $\mathrm{pCg}$ & $\mathbf{P u}$ & Th & $\mathrm{Tp}$ \\
\hline INDTD01 & 3.01 & 1.94 & 1.41 & 1.72 & 1.92 & 2.52 & 1.08 & 2.37 \\
\hline INDTD02 & 3.03 & 2.05 & 1.63 & 1.76 & 1.04 & 2.35 & 1.30 & 2.35 \\
\hline INDTD07 & 3.31 & 2.04 & 1.50 & 1.76 & 2.07 & 2.70 & 1.60 & 2.56 \\
\hline INDTD08 & 3.01 & 2.02 & 1.57 & 1.83 & 1.97 & 2.64 & 1.32 & 2.50 \\
\hline INDTD14 & 2.12 & 1.41 & 1.16 & 1.43 & 1.72 & 1.85 & 1.06 & 1.68 \\
\hline INDTD16 & 2.68 & 1.61 & 1.20 & 1.26 & 1.42 & 2.03 & 2.24 & 1.84 \\
\hline INDTD17 & 2.63 & 1.82 & 1.37 & 1.36 & 1.55 & 2.03 & 1.16 & 2.04 \\
\hline INDTD30 & 2.42 & 1.73 & 1.26 & 1.14 & 1.26 & 1.87 & 1.08 & 2.17 \\
\hline INDTD35 & 3.82 & 1.90 & 1.74 & 1.86 & 2.15 & 2.48 & 1.43 & 2.39 \\
\hline INDTD47 & 2.09 & 1.29 & 2.17 & 1.41 & 1.86 & 1.95 & 1.02 & 2.74 \\
\hline INDTD48 & 3.30 & 1.76 & 1.94 & 1.95 & 2.25 & 2.49 & 1.51 & 2.51 \\
\hline INDTD49 & 2.75 & 1.57 & 1.32 & 1.56 & 1.46 & 2.19 & 1.07 & 2.10 \\
\hline JHUTD4 & 2.80 & 3.19 & 3.48 & 4.31 & 3.39 & 3.08 & 1.43 & 4.54 \\
\hline JHUTD6 & 3.38 & 3.57 & 3.69 & 4.48 & 3.65 & 3.16 & 1.32 & 4.94 \\
\hline JHUTD14 & 2.47 & 3.24 & 3.15 & 3.73 & 3.44 & 2.94 & 1.41 & 4.09 \\
\hline JHUTD105 & 3.73 & . & 2.86 & . & . & 3.30 & 2.11 & 3.73 \\
\hline JHUTD1001 & 4.59 & . & 3.64 & . & . & 4.29 & 2.57 & 4.86 \\
\hline JHUTD1002 & 3.83 & . & 2.77 & . & . & 3.66 & 2.21 & 3.73 \\
\hline JHUTD1005 & 3.58 & . & 2.77 & . & . & 3.24 & 2.02 & 3.26 \\
\hline JHUASD3 & 2.17 & 3.06 & 3.26 & 4.05 & 3.43 & 3.87 & 1.27 & 3.97 \\
\hline JHUASD4 & 2.62 & 3.43 & 3.10 & 4.17 & 3.99 & 3.03 & 1.45 & 3.85 \\
\hline JHUASD5 & 2.79 & 3.25 & 3.48 & 3.84 & 3.25 & 2.78 & 1.46 & 4.17 \\
\hline JHUASD7 & 3.13 & & 2.03 & 2.74 & & 2.84 & 1.67 & 2.72 \\
\hline JHUASD8 & 3.12 & 3.54 & 3.42 & 4.18 & 3.74 & 3.36 & 1.55 & 4.21 \\
\hline JHUASD9 & 3.06 & 3.35 & 3.43 & 4.23 & 3.64 & 3.36 & 1.32 & 4.58 \\
\hline JHUASD12 & 3.25 & 2.46 & 3.41 & 4.11 & 3.34 & 2.99 & 1.75 & 4.58 \\
\hline INDFXS34 & 1.96 & 1.00 & 1.06 & 1.42 & 1.37 & 2.01 & 0.83 & 1.40 \\
\hline INDFXS38 & 1.58 & 0.69 & 0.59 & 0.82 & 0.79 & 1.08 & 0.61 & 0.92 \\
\hline INDFXS40 & 1.65 & 0.81 & 0.82 & 0.96 & 1.40 & 1.13 & 0.39 & 1.14 \\
\hline INDFXS41 & 2.14 & 1.25 & 1.08 & 1.36 & 1.56 & 1.65 & 0.56 & 1.59 \\
\hline INDFXS42 & 3.45 & 2.24 & 1.78 & 2.09 & 2.18 & 2.55 & 1.25 & 2.68 \\
\hline INDFXS44 & 1.76 & 1.01 & 1.03 & 1.23 & 1.23 & 1.69 & 0.73 & 1.37 \\
\hline INDFXS45 & 2.89 & 1.74 & 1.47 & 1.73 & 1.91 & 2.16 & 1.32 & 2.13 \\
\hline $\begin{array}{l}\text { INDFXS- } \\
\text { M50 }\end{array}$ & 2.99 & 2.24 & 1.73 & 1.77 & 1.82 & 2.50 & 1.19 & 2.53 \\
\hline JHUFXS2 & 2.05 & 2.71 & . & . & 3.01 & 2.01 & 0.97 & . \\
\hline JHUFXS4 & 2.00 & 2.21 & . & 2.7 & 2.25 & 1.98 & 0.89 & . \\
\hline
\end{tabular}

CN: Caudate nucleus; mTp: Medial temporal cortex; Oc: Occipital cortex; Pa: Parietal cortex; pCg: Posterior cingulate cortex; Pu: Putamen; Th: Thalamus; Tp: Temporal cortex.

The ages of participants with IASD were lower than those with FXS and TD (Table 1) $[17,26,29]$. BMIs were ordered IASD $<$ TD $<$ FXS (Table 1) $[17,26,29]$.

mGluR $_{5}$ uptake was ordered FXS $<$ TD $<$ IASD in cortical $(\mathrm{Oc}, \mathrm{Pa}, \mathrm{Tp}$, and $\mathrm{pCg})$ structures (Figure 2) [26,30]. 


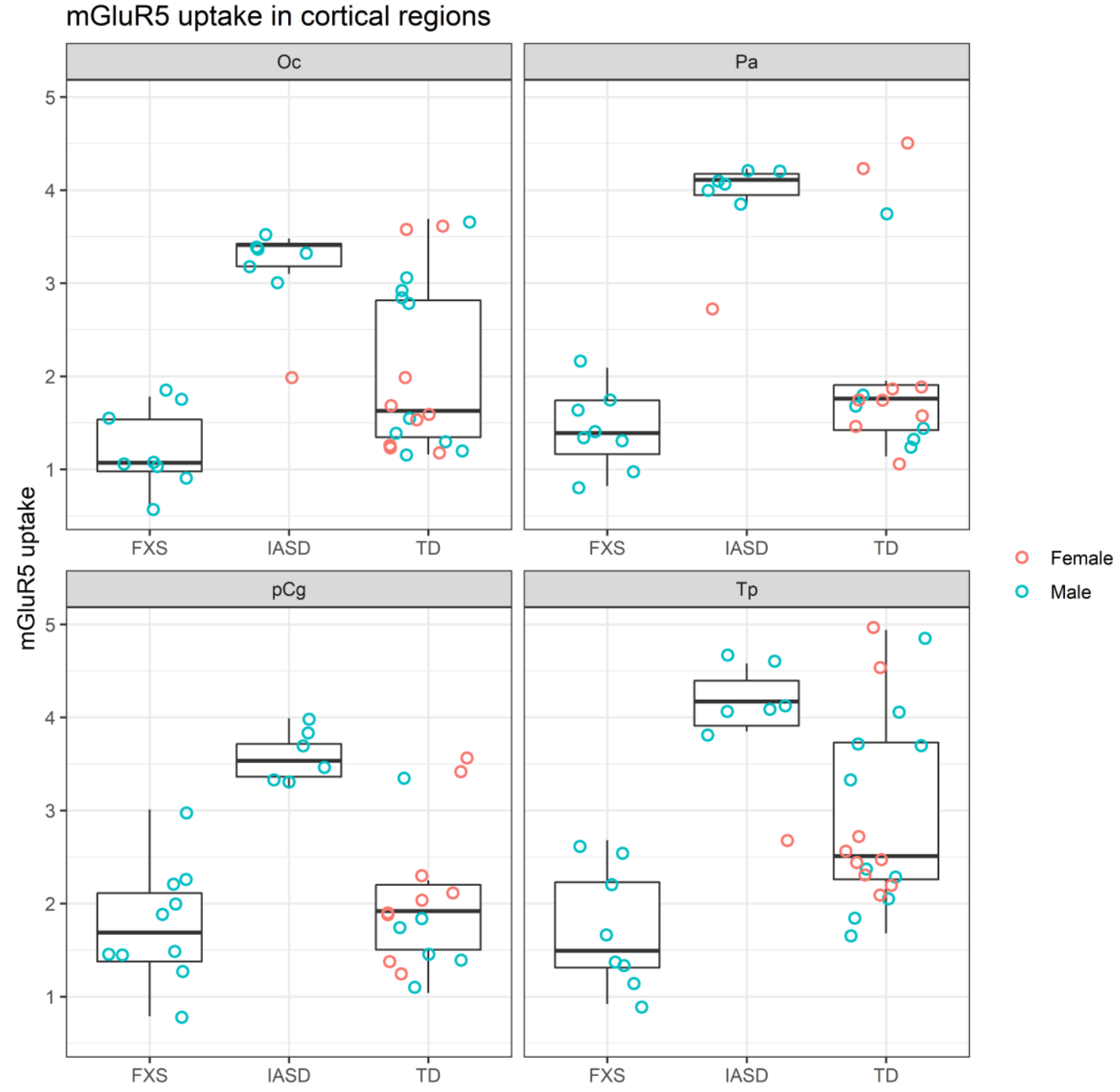

Figure 2. mGluR $_{5}$ uptake in cortical regions of participants grouped by cohort [26,30]. FXS: Fragile X syndrome; IASD: Idiopathic autism spectrum disorder; $\mathrm{mGluR}_{5}$ : Metabotropic glutamate receptor subtype 5; Oc: Occipital cortex; Pa: Parietal cortex; pCg: Posterior cingulate cortex; TD: Typical development; Tp: Temporal cortex.

By contrast $\mathrm{mGluR}_{5}$ uptake was lower in participants with FXS than in participants with TD and IASD in subcortical (CN, Pu, and Th) structures (Figure 3) [26,30].

The initial visual analysis of the data indicated that the $\mathrm{mGluR}_{5}$ uptake differed across the groups of FXS, IASD, and TD in multiple regions. Analysis of variance (ANOVA) confirmed that group had a significant effect across all regions (d.f. $=2, \mathrm{~F}=51.6, p<0.001$ ) (Table 3) [30]. Post hoc pair-wise comparisons using Tukey's Honest Standard Differences (HSD) method further confirmed specific differences (Table 4) [30,31]. The pairwise comparisons highlighted the largest group differences in the temporal cortex (adjusted mean difference, FXS versus IASD $=-2.19 \pm 0.49(p<0.001)$ the parietal cortex (FXS versus IASD $=-2.31 \pm 0.48, p<0.001)$, and the occipital cortex (FXS versus IASD $=-1.88 \pm 0.41$, $p<0.001)[30,31]$. 
mGluR5 uptake in subcortical regions
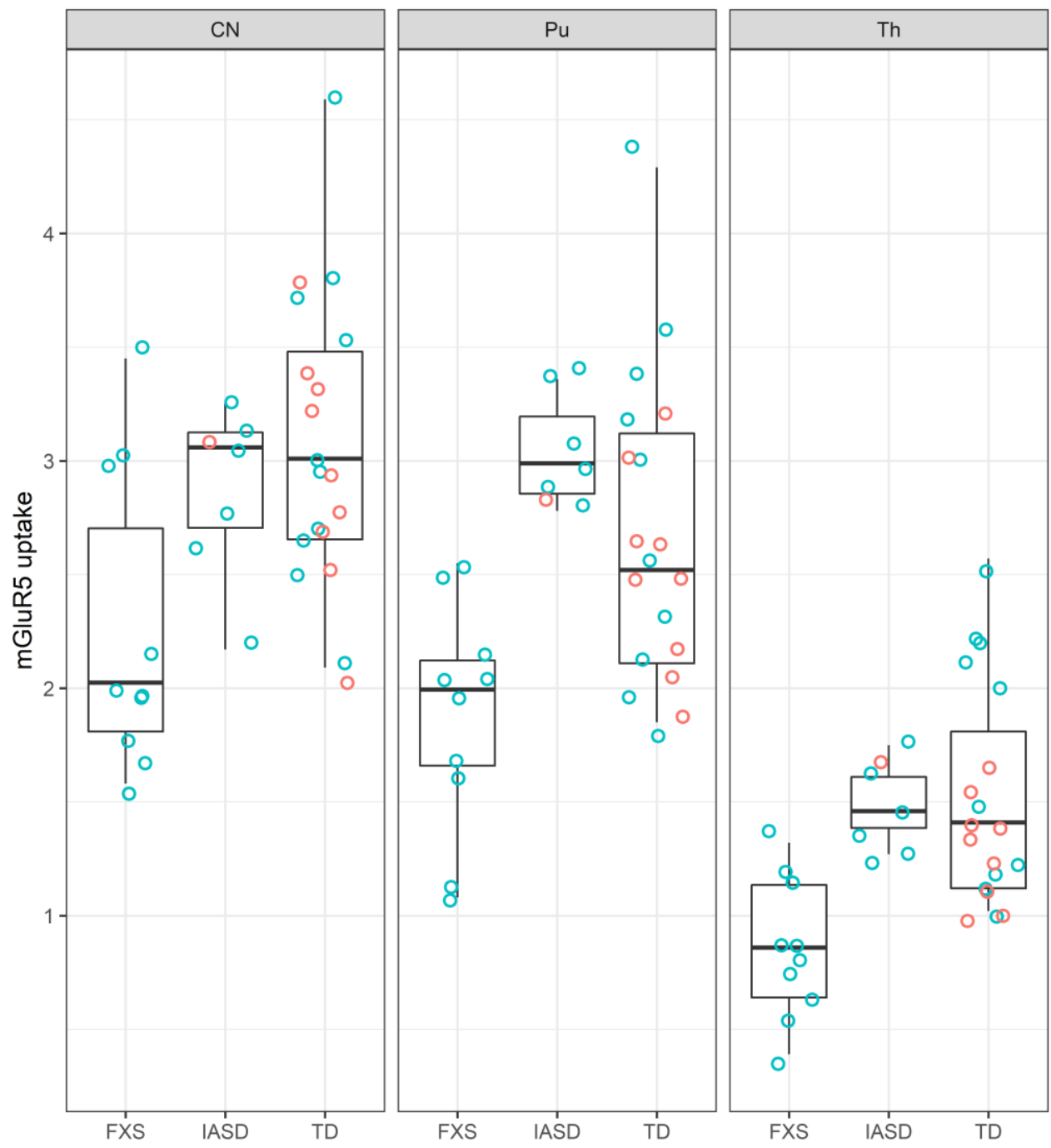

Female

- Male

Figure 3. mGluR $_{5}$ uptake in subcortical regions of participants grouped by cohort [26,30]. CN: Caudate nucleus; FXS: Fragile X syndrome; IASD: Idiopathic autism spectrum disorder; GluR $_{5}$ : Metabotropic glutamate receptor subtype 5; Pu: Putamen; TD: Typical development; Th: Thalamus.

Table 3. Analysis of variance of mGluR $_{5}$ uptake by group (FXS, IASD, and TD) and region [30].

\begin{tabular}{cccc}
\hline & \multicolumn{2}{c}{ Analysis of Variance by Group Status and Region } \\
\hline Region & Degrees of freedom & Test statistic & Probability \\
\hline Caudate nucleus & 2 & 6.77 & 0.00364 \\
\hline Occipital cortex & 2 & 12.8 & 0.00010 \\
\hline Parietal cortex & 2 & 16.2 & 0.00003 \\
\hline Posterior cingulate cortex & 2 & 14.6 & 0.00006 \\
\hline Putamen & 2 & 10.1 & 0.00043 \\
\hline Thalamus & 2 & 10.3 & 0.00038 \\
\hline Temporal cortex & 2 & 12.3 & 0.00014 \\
\hline
\end{tabular}

FXS: Fragile X syndrome; IASD: Idiopathic autism spectrum disorder; GluR $_{5}$ : Metabotropic glutamate receptor subtype 5; TD: Typical development. 
Table 4. Post hoc pairwise comparisons of $\mathrm{mGluR}_{5}$ uptake by group (FXS, IASD, and TD) and region [30,31].

\begin{tabular}{|c|c|c|c|c|}
\hline \multicolumn{5}{|c|}{ Post hoc Pairwise Comparisons by Tukey's Honest Standard Differences $[30,31]$} \\
\hline Region & Pairwise Comparison & Adjusted Mean Difference & Standard Error & Probability \\
\hline \multirow{3}{*}{ Caudate nucleus } & FXS-IASD & -0.81837 & 0.301489 & 0.028089 \\
\hline & TD-IASD & -0.02072 & 0.298712 & 0.997341 \\
\hline & TD-FXS & 0.797653 & 0.259542 & 0.011671 \\
\hline \multirow{3}{*}{ Occipital cortex } & FXS-IASD & -1.88121 & 0.409271 & 0.000218 \\
\hline & TD-IASD & -0.74904 & 0.384949 & 0.143727 \\
\hline & TD-FXS & 1.132169 & 0.353062 & 0.008855 \\
\hline \multirow{3}{*}{ Parietal cortex } & FXS-IASD & -2.31154 & 0.476181 & 0.000173 \\
\hline & TD-IASD & -1.56255 & 0.493592 & 0.010802 \\
\hline & TD-FXS & 0.748987 & 0.462568 & 0.25626 \\
\hline \multirow{3}{*}{ Posterior cingulate cortex } & FXS-IASD & -1.6965 & 0.362152 & 0.000203 \\
\hline & TD-IASD & -1.5125 & 0.425317 & 0.00414 \\
\hline & TD-FXS & 0.184006 & 0.356537 & 0.863175 \\
\hline \multirow{3}{*}{ Putamen } & FXS-IASD & -1.23401 & 0.29236 & 0.000529 \\
\hline & TD-IASD & -0.31288 & 0.289668 & 0.532202 \\
\hline & TD-FXS & 0.921134 & 0.251683 & 0.002488 \\
\hline \multirow{3}{*}{ Thalamus } & FXS-IASD & -0.69753 & 0.197012 & 0.003572 \\
\hline & TD-IASD & 0.084401 & 0.195197 & 0.902066 \\
\hline & TD-FXS & 0.781931 & 0.169601 & 0.000214 \\
\hline \multirow{3}{*}{ Temporal cortex } & FXS-IASD & -2.18986 & 0.490827 & 0.000294 \\
\hline & TD-IASD & -0.75798 & 0.461658 & 0.243837 \\
\hline & TD-FXS & 1.431881 & 0.423417 & 0.005678 \\
\hline
\end{tabular}

FXS: Fragile X syndrome; IASD: Idiopathic autism spectrum disorder; GluR $^{5}$ : Metabotropic glutamate receptor subtype 5; TD: Typical development.

\section{Discussion}

We confirmed our earlier finding that mGluR $_{5}$ expression is reduced in all brain regions in men with FXS [17] on a sample of men with FXS compared to participants of both sexes with IASD $[14,23]$ and TD $[14,17,25,26]$. In men with FXS, reduced mGluR $_{5}$ expression in (A) cortical regions provides a basis for ID and (B) limbic regions provides a basis for the neurobehavioral symptoms $[10,17]$.

We expanded our finding of increased mGluR $_{5}$ expression in the postcenteral gyrus and cerebellum of men with IASD [14] to show increased GGluR $_{5}$ expression in cortical regions of a sample from two separate institutions (IND and JHU) that includes participants with IASD and TD of both sexes. There are several possible explanations for the opposite results in IASD versus FXS. First, there may be different characteristic mechanisms for the development of $\mathrm{mGluR}_{5}$ expression in IASD and FXS. Second, there may be other characteristics of these cohorts, specifically age and ID, that caused the differences in mGluR $_{5}$ expression in the cohorts with FXS and IASD. The participants with IASD were all younger than the participants with FXS. There may be reductions in $\mathrm{mGluR}_{5}$ expression correlated with age as for dopamine D2 and serotonin S2 receptors [32]. Additionally all participants with IASD were recruited from samples with high-functioning autism; all participants with IASD had normal or superior intelligence. By contrast all participants with FXS had ID. Therefore, the opposite results of mGluR $_{5}$ expression in IASD versus FXS may simply reflect the differences in age and ID between the cohorts. The opposite results 
of mGluR 5 expression in IASD versus FXS may therefore be unrelated to the diagnosis of FXS and IASD.

These findings confirm the hypothesis that $\mathrm{mGluR}_{5}$ expression plays a role in the pathogenesis of FXS and other subtypes of IASD. The protocol for this investigation provides a feasibility tool that may facilitate the measurement of a biomarker of $\mathrm{mGluR}_{5}$ expression to conduct rigorously designed clinical trials of FXS [9] and perhaps other subtypes of IASD. That said, the findings of this study merit replication in a larger sample of the groups studied here and other neurodevelopmental disorders [33]. Indeed the current protocol may be expanded to promote knowledge about multiple neuromodulators in FXS, Rett syndrome $[34,35]$ and other subtypes of IASD.

Limitations. Estimation of binding potential for participants from IND as [standard uptake value ratio (SUVR)-1] [36] introduced uncertainty in the analysis [17]. Additionally the comparison of results from IND and JHU was confounded by the use of differences in scanners, scanning times, and analysis $[17,26]$. The similarity of results from both IND and JHU suggests the presence of convergent validity that the findings represent the characteristics of the status (IASD, FXS, and TD) of the participants. Future investigations will be enhanced by contemporaneous conduct of all investigations at all participating institutions with identical protocols and analyses [17].

Additionally, since some participants with TD are much older than other participants, the age difference may represent a confounding influence. $\mathrm{mGluR}_{5}$ density may be reduced with age just as the density of dopamine D2 and serotonin S2 receptors is reduced with age [32]. The variability of BMIs may represent another confounding influence. Since all participants with IASD were high-functioning $[14,23,26]$, both samples of participants with IASD and TD lacked the intellectual disability (ID) that characterized the sample of males with FXS $[17,26]$.

Future directions. Our finding of increased $\mathrm{mGluR}_{5}$ in the post central gyrus and cerebellum of men with IASD [14] was expanded in the current report with a sample of participants with IASD and TD of both sexes and men with FXS. We confirmed the reductions in mGluR $_{5}$ in all regions in men with FXS [17]. We showed increased GluR $_{5}$ in cortical regions of participants with IASD. A study of the left striatum of a different cohort of participants with ID and TD demonstrated a trend of increased $\mathrm{mGluR}_{5}$ in participants with IASD by PET with $\left[{ }^{18} \mathrm{~F}\right] \mathrm{FPEB}$, no change in glutamate by magnetic resonance spectroscopy (MRS), a trend of decreased gamma amino butyric acid (GABA) by MRS, and a strong negative correlation between $\mathrm{mGluR}_{5}$ and GABA [37]. This finding supports the hypothesis of abnormal excitatory/inhibitory ratio in participants with IASD [2] and merits expansion and confirmation in other cohorts using both PET and MRS to assess both mGluR $_{5}$ and GABA.

Future investigations utilizing the protocol of this study may provide the tools for successful clinical trials of negative allosteric modulators (NAMs) for FXS and IASD. Despite the evidence that NAMs ameliorate behavioral symptoms in animal models of FXS, there have not been beneficial effects demonstrated in multiple clinical trials of NAMs in FXS. Flaws in the design of the clinical trials including the absence of a tool to measure mGluR $_{5}$ expression in the living human brains of participants with FXS have been identified as likely explanations for the unsuccessful clinical trial of NAMs in FXS [9]. Therefore, utilization of the procedure in this study may provide the crucial tool to generate rigorous measurements to demonstrate beneficial neurobehavioral effects of NAMs in clinical trials of FXS and IASD and related conditions.

Additional investigations will be enhanced with multiple imaging techniques including PET, MRS, PET/MRI [38], electroencephalography (EEG) [39,40], event-related brain potential (ERP) [39-41], resting state functional magnetic resonance imaging (rs-fMRI), diffusion tensor imaging (DTI), movement measurements [42], and quantitative measurements of FMRP and the FMR1 gene [43]. Further prospective studies of ASD [44] may be enhanced by including these measurement tools, neuropsychological assessments, and whole exome sequencing (WES) [45]. The evidence for decreased expression of FMRP in 
IASD [46] and FXS [43] indicates that correlation of FMRP with mGluR 5 [43,46] and GABA in ASD [37] is appropriate for future studies.

\section{Materials and Methods}

\subsection{Participants}

\subsubsection{Recruiting Sites}

The study is approved by Johns Hopkins Medicine Institutional Review Board IRB 169,249 [17]. The protocols for the study of humans were approved by the Institutional Review Boards of the Institute for Neurodegenerative Disorders (IND) in New Haven, Connecticut [47] and the Johns Hopkins University (JHU) in Baltimore, Maryland [48,49]. Since exposure to radioactivity in PET constitutes greater than minimal risk, this pilot study was restricted to adults [17]. Written informed consent was obtained from each participant at both locations.

We report the findings of cohorts of independent investigations conducted at the IND on seven men with FXS (mean age $27 \pm 4.76$, range 12 years) $[17,26]$, one man with fragile $\mathrm{X}$ syndrome allele size mosaicism (FXS-M) aged 56.6 years $[17,26]$, and five men and six women with TD (mean age $38.27 \pm 15.68$, range 42 years) $[17,26]$, and at the JHU on two men with FXS (mean age $25.5 \pm 2.12$, range 3 years), six men and one woman with IASD (mean age $19.71 \pm 2.06$, range 5 years), and five men and two women with TD (mean age $26.57 \pm 7.14$ range 20 years) $[14,17,23,25,26]$. In contrast to the participants with FXS and FXS-M, all participants with IASD and TD had no evidence of intellectual disability (ID) [26]. In order to maximize the size effect, this report with focus on the combined sample of participants with IASD $(N=7$, age $19.71 \pm 2.06), \mathrm{FXS}(N=10$, age $29.7 \pm 10.39)$, and TD $(N=19$, age $34.89 \pm 14.57)[26,29]$.

\subsubsection{Inclusion Criteria}

Inclusion criteria for all participants included age between 18-60 years. Participants with IASD had a diagnosis of autism based on the Autism Diagnostic InterviewRevised [14,23,50], the Autism Diagnostic Observation Schedule [14,23,51], the Diagnostic and Statistical Manual of Mental Disorders, Fifth Edition (DSM-5) [1,14], and other diagnostic tools documented in our prior publication $[14,17,26]$. Participants with FXS had a diagnosis of FXS based on FMR1 DNA gene testing by polymerase chain reaction (PCR)/Southern Blot, supplemented by clinical neurobehavioral profiling $[17,26,43]$.

\subsubsection{Exclusion Criteria}

Exclusion criteria were clinically significant abnormal laboratory values and/or clinically significant unstable serious medical, neurological, or psychiatric illnesses $[14,17,47]$.

\subsection{Procedures}

\subsubsection{Positron Emission Tomography (PET)}

All participants underwent scans conducted by an experienced research staff of Certified Nuclear Medicine Technologists (CNMT) who had attained certification by the Nuclear Medicine Technology Certification Board (NMTCB). The technologists had conducted many PET scans before this study. The technologists maintained the physical conditions of each scan optimally for the completion of the scans. Participants were positioned by the technologists in the most comfortable manner for scans. Heads were stabilized in the scanner by gauge strips at IND and by face masks at JHU [17,34]. In order to maintain a comfortable environment during the scans, technologists utilized blankets and pads to raise legs. The physical conditions of the scans were maintained in optimal manners for participants by outstanding technologists.

Positron emission tomography (PET) after the intravenous bolus injection $185 \mathrm{MBq}$ (5 mCi) of $\left[{ }^{18} \mathrm{~F}\right]$ FPEB $[14,17,23,26]$ was conducted at IND on an ECAT EXACT HR+ PET manufactured by Siemens/CTI (Knoxville, TN) [52] for 90-120 min after injection and at JHU on an ECAT high resolution research tomograph (HRRT) manufactured by 
Siemens/CTI (Knoxville, TN) [53] for 0-90 min after injection. Injectors obtained measured doses of $\left.{ }^{18} \mathrm{~F}\right] \mathrm{FPEB}$ synthesized by radiochemists in the adjacent radiochemistry laboratory following the published methods [25] to be administered to participants in the scanning chambers.

\subsubsection{Statistical Analyses}

Data for participants from IND were expressed as the standard uptake value ratio (SUVR) with the cerebellum as reference region because there is minimal radio tracer uptake in the cerebellum $[26,54]$. Assuming that there is no difference in nonspecific tracer binding between regions and between participant cohorts, we approximated nondisplaceable binding potentials $\left(\mathrm{BP}_{\mathrm{ND}}\right)[17,26]$ as the (SUVR-1) [36] for participants from IND (Table 2).

Data for participants from JHU were represented as regional nondisplaceable binding potentials $\left(\mathrm{BP}_{\mathrm{ND}} \mathrm{s}\right)[14,17,23,26]$ by reference tissue graphical analysis (RTGA) [55] with the cerebellar white matter as the reference region $[14,17,25,26,54]$.

Due to the small sample size we expressed the results for the combined cohorts from IND and JHU as dot plots with box plots representing descriptive statistics utilizing $\mathrm{R}(\mathrm{R}$ Foundation, Vienna, Austria) [30].

After constructing the plots of our data, several group differences were observed across the regions tested. To confirm the effect of group status (e.g., FXS versus TD versus IASD), we used analysis of variance (ANOVA) utilizing R (R Foundation, Vienna, Austria) [30], using group and region as the main factors, with age and sex as covariates. As the ANOVA showed evidence of a significant effect of group on mGluR 5 uptake, we then conducted post hoc pairwise comparisons with Tukey's Honest Standard Differences (HSD) utilizing R (R Foundation, Vienna, Austria) [30,31]. HSD was chosen as the more traditional Bonferroni correction lacked statistical power given our smaller sample size.

\section{Conclusions}

We confirmed our earlier finding of reduced cerebral mGluR $_{5}$ expression [17] in a sample of men with FXS in contrast to participants with IASD and TD of both sexes. The significantly reduced $\mathrm{mGluR}_{5}$ expression in all brain regions of men with FXS provides a possible molecular basis for the neurobehavioral phenotype of individuals with FXS [10]. Reduced cortical mGluR 5 expression may provide a basis for the cognitive deficits (delayed socialization) of individuals with FXS [56]. Reduced limbic mGluR $_{5}$ expression may provide a basis for the avoidance behaviors of individuals with FXS [56].

We showed increased cortical cerebral $\mathrm{mGluR}_{5}$ expression in participants of both sexes with IASD in contrast to participants with TD and men with FXS. Since all participants with IASD were recruited initially for studies of children with high-functioning autism, the increased cortical cerebral $\mathrm{mGluR}_{5}$ expression may represent a molecular feature of IASD or of superior intelligence.

The proposed protocol may provide a biomarker for measurement of $\mathrm{mGluR}_{5}$ expression for clinical trials of FXS and other subtypes of ASD. The proposed protocol may provide a tool to utilize precision medicine for diagnostic and therapeutic interventions for ASD and related conditions.

Author Contributions: Conceptualization, J.R.B., D.S.R., D.F.W. and D.B.B.; data curation, J.R.B., A.N., D.S.R., D.J., O.B., S.D.M., D.F.W. and D.B.B.; formal analysis, J.R.B., A.N., O.B., D.F.W. and D.B.B.; funding acquisition, J.R.B., D.S.R., D.F.W. and D.B.B.; investigation, J.R.B., A.N., D.S.R., D.J., S.D.M., K.S., T.S., J.P.S., D.F.W. and D.B.B.; methodology, J.R.B., A.N., D.S.R., D.J., O.B., S.D.M., K.S., T.S., J.P.S., D.F.W. and D.B.B.; project administration, J.R.B., A.N., D.S.R., D.J., J.P.S., D.F.W. and D.B.B.; resources, J.R.B., A.N., D.S.R., O.B., K.S., T.S., J.P.S., D.F.W. and D.B.B.; software, J.R.B., A.N., O.B. and S.D.M.; supervision, J.R.B., D.S.R., K.S., T.S., J.P.S., D.F.W. and D.B.B.; validation, J.R.B., A.N., D.S.R., D.J., O.B., S.D.M., K.S., T.S., J.P.S., D.F.W. and D.B.B.; visualization, J.R.B., A.N., D.S.R., D.J., O.B., S.D.M., J.P.S., D.F.W. and D.B.B.; and editing, J.R.B., A.N., D.S.R., S.D.M. and D.B.B. All authors have read and agreed to the published version of the manuscript. 
Funding: This research was made possible by a Radiology BRidge/Development Funding Initiative to STimulate and Advance Research (RAD BriteStar Bridge) Award from the Johns Hopkins University School of Medicine, Baltimore, Maryland to J.R.B. with the assistance of D.F.W.; the Intellectual \& Developmental Disabilities Research Center (U54 HD079123), Kennedy Krieger Institute, and Johns Hopkins Medical Institutions, Baltimore, Maryland, vto J.R.B.; and the Johns Hopkins Institute for Clinical and Translational Research (ICTR), Johns Hopkins University School of Medicine, Baltimore, Maryland, to J.R.B., which is funded in part by Grant Number UL1 TR003098 from the National Center for Advancing Translational Sciences (NCATS), a component of the National Institutes of Health (NIH), and NIH Roadmap for Medical Research. Its contents are solely the responsibility of the authors and do not necessarily represent the official view of the Johns Hopkins ICTR, NCATS, or NIH.

Institutional Review Board Statement: The study was conducted according to the guidelines of the Declaration of Helsinki [49], and approved by the Institutional Review Board of the Johns Hopkins School of Medicine in Baltimore, Maryland (Protocol Number: IRB00169249 and Initial Approval Date: 11 July 2018).

Informed Consent Statement: Informed consent was obtained from all subjects involved in the study.

Data Availability Statement: The data presented in this study are openly available in [Zenodo]. Available online: https:/ / doi.org/10.5281/zenodo.4395102 (accessed on 6 March 2021) [26].

Acknowledgments: The authors thank the patients and families for their participation and dedication to these studies; they are the inspiration for our efforts at improving treatments. The authors thank the FORWARD Database and Registry of the National Fragile X Foundation (NFXF) funded by the Centers for Disease Control and Prevention (CDC), Atlanta, Georgia, for referral of participants. The authors thank the teams of the Institute of Neurodegenerative Disorders, the Positron Emission Tomography (PET) Radiotracer Service Center, and the Research Magnetic Resonance Imaging (MRI) Service Center of the Johns Hopkins University School of Medicine for conducting the scans. The authors thank Hiroto Kuwabara for PET analysis. The authors thank Brian Hwang for posing for the photograph by J.R.B. on the Graphical Abstract/Earlier versions of this article were presented at the 2020 Annual Meeting, Society of Nuclear Medicine and Molecular Imaging, 11-14 July 2020, the World Molecular Imaging Congress 2020, and the Society for Neuroscience Global Connectome, Virtual [43].

Conflicts of Interest: The authors declare no conflict of interest. The funders had no role in the design of the study; in the collection, analyses, or interpretation of data; in the writing of the manuscript, or in the decision to publish the results.

\author{
Abbreviations \\ $\left[{ }^{18}\right.$ F]FPEB 3-[ ${ }^{18}$ F $]$ fluoro-5-(2-pyridinylethynyl)benzonitrile \\ ADI-R Autism Diagnostic Interview-Revised [50] \\ ADOS Autism Diagnostic Observation Schedule [51] \\ ANOVA analysis of variance \\ ASD autism spectrum disorder \\ BMI basal metabolic index \\ $\mathrm{BP}_{\mathrm{ND}} \quad$ non-displaceable binding potential \\ CEA Commissariat à l'Énergie Atomique et aux Énergies Alternatives \\ CDC Centers for Disease Control and Prevention \\ CN caudate nucleus \\ CNAMI CNS Neuropsychopharmacology and Multimodal Imaging \\ CNMT Certified Nuclear Medicine Technologist \\ CNRS Centre National de la Recherche Scientifique \\ CNS central nervous system \\ DSM-5 Diagnostic and Statistical Manual of Mental Disorders, Fifth Edition [1]
}




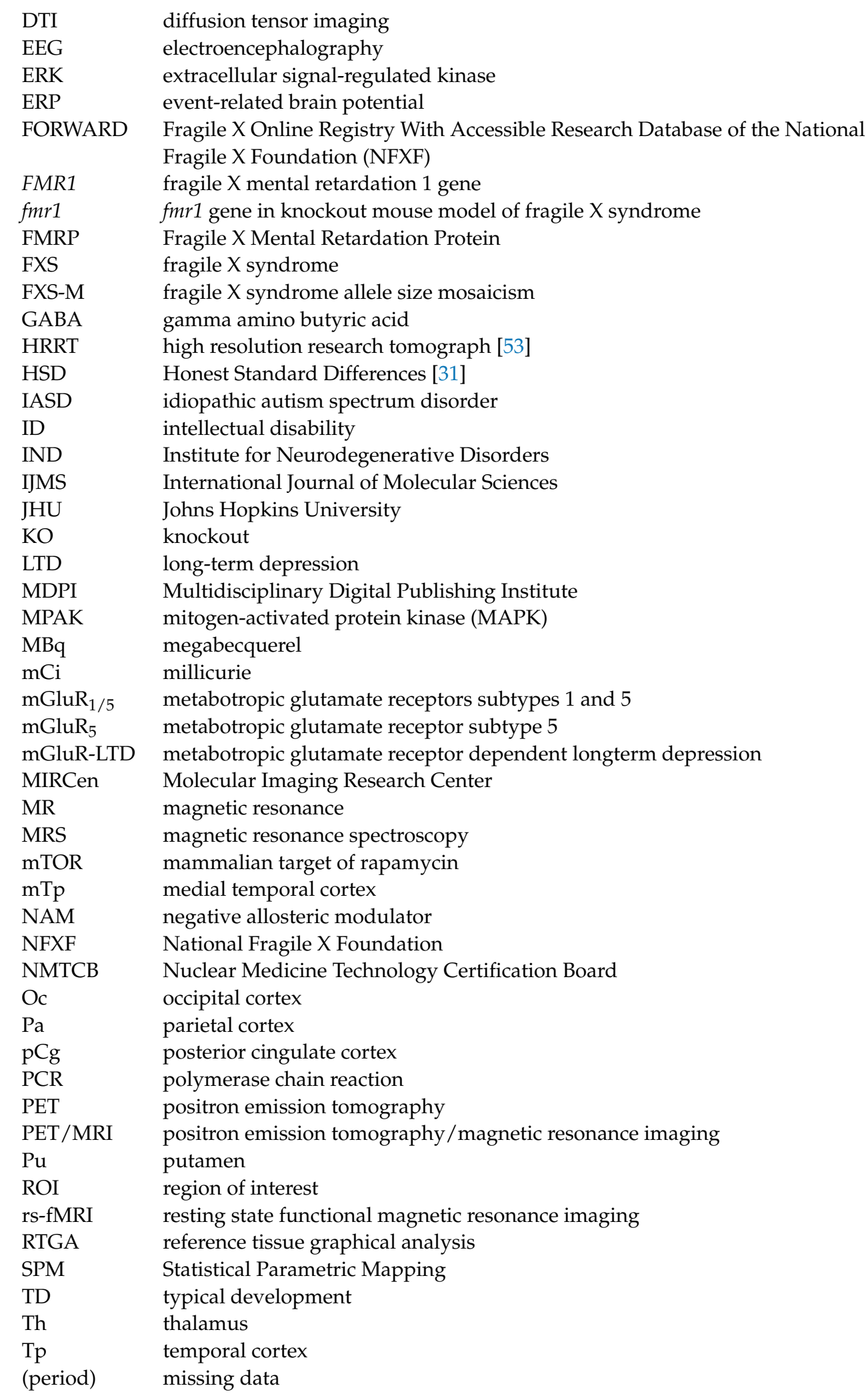

\section{References}

1. American Psychiatric Association. Diagnostic and Statistical Manual of Mental Disorders, (DSM-5), 5th ed.; American Psychiatric Association: Arlington, VA, USA, 2013.

2. Brasic, J.R.; Farhadi, F.; Elshourbagy, T. Autism Spectrum Disorder. Medscape Drugs Dis. Updated on 18 March 2020. 2020. Available online: http:/ / emedicine.medscape.com/article/912781-overview (accessed on 6 March 2021). 
3. Genovese, A.; Butler, M.G. Clinical assessment, genetics, and treatment approaches in autism spectrum disorder (ASD). Int. J. Mol. Sci. 2020, 21, 4726. [CrossRef]

4. $\quad$ Budimirovic, D.; Haas-Givler, B.; Blitz, R.; Esler, A.; Kaufmann, W.; Sudhalter, V.; Stackhouse, T.M.; Scharfenaker, S.K.; BerryKravis, E. Consensus of the Fragile X Clinical \& Research Consortium on Clinical Practices: Autism Spectrum Disorder in Fragile X Syndrome. The Fragile X Clinical \& Research Consortium. Available online: https://fragilex.org/wp-content/uploads/2012/0 8/Autism-Spectrum-Disorder-in-Fragile-X-Syndrome-2014-Nov.pdf (accessed on 6 March 2021).

5. Budimirovic, D.B.; Kaufmann, W.E. What can we learn about autism from studying fragile X syndrome? Dev. Neurosci. 2011, 33, 379-394. [CrossRef]

6. Haas-Givler, B.; Taylor, C.M.; Riley, K.; Braden, M.; Budimirovic, D.; Frazier, J.; Kinney, M.; Stackhouse, T.; Scharfenaker, S.; Kaufmann, W. Consensus of the Fragile X Clinical \& Research Consortium on Clinical Practices: Behavioral challenges in fragile X syndrome. The Fragile X Clinical \& Research Consortium. 2018. Available online: https://fragilex.org/wp-content/uploads/ 2018/12/Behavior-Challenges-in-Fragile-X-Treatment-Guidelines.pdf (accessed on 6 March 2021).

7. Jeśko, H.; Cieślik, M.; Gromadzka, G.; Adamczyk, A. Dysfunctional proteins in neuropsychiatric disorders: From neurodegeneration to autism spectrum disorders. Neurochem. Int. 2020, 141, 104853. [CrossRef] [PubMed]

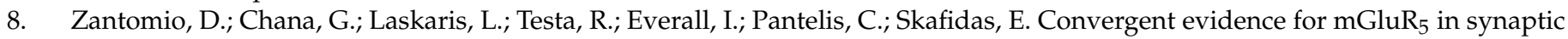
and neuroinflammatory pathways implicated in ASD. Neurosci. Biobehav. Rev. 2015, 52, 172-177. [CrossRef] [PubMed]

9. Budimirovic, D.B.; Berry-Kravis, E.; Erickson, C.A.; Hall, S.S.; Hessl, D.; Reiss, A.L.; King, M.K.; Abbeduto, L.; Kaufmann, W.E. Updated report on tools to measure outcomes of clinical trials in fragile X syndrome. J. Neurodev. Disord. 2017, 9, 14. [CrossRef]

10. Budimirovic, D.B.; Schlageter, A.; Filopovic-Sadic, S.; Protic, D.D.; Bram, E.; Mahone, E.M.; Nicholson, K.; Culp, K.; Javanmardi, K.; Kemppainnen, J.; et al. A genotype-phenotype study of high-resolution FMR1 nucleic acid and protein analyses in fragile $\mathrm{X}$ patients with neurobehavioral assessments. Brain Sci. 2020, 10, 694. [CrossRef]

11. Budimirovic, D.B.; Subramanian, M. Neurobiology of Autism and Intellectual Disability: Fragile X Syndrome. In Neurobiology of Disease, 2nd ed.; Johnston, M.V., Ed.; Oxford University Press: New York, NY, USA, 2016; pp. 375-384.

12. Duy, P.Q.; Budimirovic, D.B. Fragile $X$ syndrome: Lessons learned from the most translated neurodevelopmental disorder in clinical trials. Transl. Neurosci. 2017, 8, 7-8. [CrossRef]

13. Chana, G.; Laskaris, L.; Pantelis, C.; Gillett, P.; Testa, R.; Zantomio, D.; Burrows, E.L.; Hannan, A.J.; Everall, I.P.; Skafidas, E. Decreased expression of mGluR $_{5}$ within the dorsolateral prefrontal cortex in autism and increased microglial number in $\mathrm{mGluR}_{5}$ knockout mice: Pathophysiological and neurobehavioral implications. Brain Behav. Immun. 2015, 49, 197-205. [CrossRef] [PubMed]

14. Fatemi, S.H.; Wong, D.F.; Brašić, J.R.; Kuwabara, H.; Mathur, A.; Folsom, T.D.; Jacob, S.; Realmuto, G.M.; Pardo, J.V.; Lee, S. Metabotropic glutamate receptor 5 tracer $\left[{ }^{18} \mathrm{~F}\right]-F P E B$ displays increased binding potential in postcentral gyrus and cerebellum of male individuals with autism: A pilot PET study. Cerebellum Ataxias 2018, 5, 3. Available online: http://rdcu.be/GQb3 (accessed on 6 March 2021). [CrossRef]

15. van Gelder, C.A.G.H.; Penning, R.; Veth, T.S.; Catsburg, L.A.D.; Hoogenraad, C.C.; MacGillavry, H.D.; Altelaar, M. Temporal quantitative proteomics of mGluR-induced protein translation and phosphorylation in neurons. Mol. Cell. Proteomics 2020, 19, 1952-1967. [CrossRef]

16. Bear, M.F.; Huber, K.M.; Warren, S.T. The mGluR theory of fragile X mental retardation. Trends Neurosci. 2004, $27,370-377$. [CrossRef]

17. Brašić, J.R.; Nandi, A.; Russell, D.S.; Jennings, D.; Barret, O.; Mathur, A.; Slifer, K.; Sedlak, S.; Martin, S.D.; Brinson, Z.; et al. Reduced cerebral expression of metabotropic glutamate receptor subtype 5 in men with fragile X syndrome. Brain Sci. 2020, 10, 899. [CrossRef] [PubMed]

18. Eltokhi, A.; Santuy, A.; Merchan-Perez, A.; Sprengel, R. Glutamatergic dysfunction and synaptic ultrastructural alterations in schizophrenia and autism spectrum disorder: Evidence from human and rodent studies. Int. J. Mol. Sci. 2021, 22, 59. [CrossRef] [PubMed]

19. Basilico, B.; Morandell, J.; Novarino, G. Molecular mechanisms for targeted ASD treatments. Curr. Opin. Genet. Dev. 2020, 65, 126-137. [CrossRef] [PubMed]

20. Burket, J.A.; Herndon, A.L.; Winebarger, E.E.; Jacome, L.F.; Deutsch, S.I. Complex effects of mGluR 5 antagonism on sociability and stereotypic behaviors in mice: Possible implications for the pharmacotherapy of autism spectrum disorders. Brain Res. Bull. 2011, 86, 152-158. [CrossRef] [PubMed]

21. Hooshmandi, M.; Wong, C.; Khoutorsky, A. Dysregulation of translational control signaling in autism spectrum disorders. Cell. Signal. 2020, 75, 109746. [CrossRef] [PubMed]

22. Zoicas, I.; Kornhuber, J. The role of metabotropic glutamate receptors in social behavior in rodents. Int. J. Mol. Sci. 2019, $20,1412$. [CrossRef]

23. Brasic, J.; Mishra, C.; Mathur, A.; Sweeney, K.; Folsom, T.; Kitzmiller, K.; Mellinger-Pilgrim, R.; Wong, D.; Fatemi, S. Microdose PET for the metabotropic glutamate receptor type 5 (mGluR 5 ). J. Nucl. Med. 2018, 59 (Suppl. 1), 1774. Available online: http:/ /jnm.snmjournals.org/content/59/supplement_1/1774.abstract (accessed on 6 March 2021).

24. Brasic, J.R.; Mathur, A.K.; Budimirovic, D.B. Clinical trials of pharmacological agents for developmental disabilities: Potential tools to demonstrate target engagement in children and adolescents. Md. Reg. Counc. Child Adolesc. Psychiatry (MRCCAP) 2020, $1,2$. 
25. Wong, D.F.; Waterhouse, R.; Kuwabara, H.; Kim, J.; Brašić, J.R.; Chamroonrat, W.; Stabins, M.; Holt, D.P.; Dannals, R.F.; Hamill, T.G.; et al. ${ }^{18}$ F-FPEB, a PET radiopharmaceutical for quantifying metabotropic glutamate 5 receptors: A first-in-human study of radiochemical safety, biokinetics, and radiation dosimetry. J. Nucl. Med. 2013, 54, 388-396. [CrossRef] [PubMed]

26. Brašić, J.R.; Nandi, A.; Russell, D.S.; Jennings, D.; Barret, O.; Mathur, A.; Slifer, K.; Sedlak, S.; Martin, S.D.; Brinson, Z.; et al. Reduced expression of cerebral metabotropic glutamate receptor subtype 5 in men with fragile X syndrome. Zenodo 2020 , v1. [CrossRef]

27. Innis, R.B.; Cunningham, V.J.; Delforge, J.; Fujita, M.; Gjedde, A.; Gunn, R.N.; Holden, J.; Houle, S.; Huang, S.C.; Ichise, M.; et al. Consensus nomenclature for in vivo imaging of reversibly binding radioligands. J. Cereb. Blood Flow Metab. 2007, 27, 1533-1539. [CrossRef] [PubMed]

28. Brasic, J.R.; Syed, A.B.; Farhadi, F.; Wong, D.F. PET Scanning in Autism Spectrum Disorder. Medscape Drugs Dis. Updated on 16 April 2020. 2020. Available online: http:/ / emedicine.medscape.com/article/1155568-overview (accessed on 6 March 2021).

29. Weissgerber, T.L.; Savic, M.; Winham, S.J.; Stanisavljevic, D.; Garovic, V.D.; Milic, N.M. Data visualization, bar naked: A free tool for creating interactive graphics. J. Biol. Chem. 2017, 292, 20592-20598. [CrossRef]

30. R Core Team. R: A Language and Environment for Statistical Computing; R Foundation for Statistical Computing; R Core Team: Vienna, Austria, 2020. Available online: https: / /www.R-project-org (accessed on 6 March 2021).

31. Bretz, F.; Hothorn, T.; Westfall, P. Multiple Comparisons Using R; Chapman \& Hall/CRC, Taylor and Francis Group, LLC: Boca Raton, FL, USA, 2011.

32. Wong, D.F.; Wagner, H.N.; Dannals, R.F.; Links, J.M.; Frost, J.J.; Ravert, H.T.; Wilson, A.A.; Rosenbaum, A.E.; Gjedde, A.; Douglass, K.; et al. Effects of age on dopamine and serotonin receptors measured by positron tomography in the living human brain. Science 1984, 226, 1393-1396.

33. Chugani, H.T. Positron emission tomography in pediatric neurodegenerative disorders. Pediatr. Neurol. 2019, 100, 12-25. [CrossRef] [PubMed]

34. Brašić, J.R.; Bibat, G.; Kumar, A.; Zhou, Y.; Hilton, J.; Yablonski, M.E.; Dogan, A.S.; Guevara, M.R.; Stephane, M.; Johnston, M.; et al. Correlation of the vesicular acetylcholine transporter densities in the striata to the clinical abilities of women with Rett syndrome. Synapse 2012, 66, 471-482. [CrossRef] [PubMed]

35. Wong, D.F.; Blue, M.E.; Brašić, J.R.; Nandi, A.; Valentine, H.; Stansfield, K.H.; Rousset, O.; Bibat, G.; Yablonski, M.E.; Johnston, M.V.; et al. Are dopamine receptor and transporter changes in Rett syndrome reflected in Mecp2-deficient mice? Exp. Neurol. 2018, 307, 74-81. [CrossRef] [PubMed]

36. Carson, R.E. Tracer Kinetic Modeling in PET. In Positron Emission Tomography: Basic Science and Clinical Practice; Valk, P.E., Bailey, D.L., Townsend, D.W., Maisey, M.N., Eds.; Springer-Verlag: London, UK, 2003; pp. 147-179.

37. Carey, C.; Dunn, J.; Mendez, M.A.; Velthuis, H.; Pereira, A.C.; Pretzsch, C.; Horder, J.; Veronese, M.; Lythgoe, D.; Murphy, D.; et al. $\mathrm{mGluR}_{5}$ receptor density using positron emission tomography in autism spectrum disorder versus healthy controls: Comparison with magnetic resonance spectroscopy. Eur. Neuropsychopharmacol. 2019, 29 (Suppl. 6), S540-S541.

38. Catana, C. Principles of simultaneous PET/MR imaging. Magn. Reson. Imaging Clin. N. Am. 2017, 25, 231-243. [CrossRef]

39. Elshourbagy, T.; Mousa, A.; Mohamed, M.A.; Brasic, J.R. Differentiation of zaghrouta, ululation to express joy in the Middle East, from movement disorders and other conditions. Int. J. Health Life Sci. 2021, 7, e106655. [CrossRef]

40. Razak, K.A.; Dominick, K.C.; Erickson, C.A. Developmental studies in fragile X syndrome. J. Neurodev. Disord. 2020, 12, 13. [CrossRef]

41. Li, W.; Kutas, M.; Gray, J.A.; Hagerman, R.H.; Olichney, J.M. The role of glutamate in language and language disorders-Evidence from ERP and pharmacological studies. Neurosci. Biobehav. Rev. 2020, 119, 217-241. [CrossRef]

42. McKay, G.N.; Harrigan, T.P.; Brasic, J.R. A low-cost quantitative continuous measurement of movements in the extremities of people with Parkinson's disease. MethodsX 2019, 6, 169-189. [CrossRef]

43. Martin, S.D.; Berry-Kravis, E.M.; Russell, D.R.; Jennings, D.; Barret, O.; Nandi, A.; Seibyl, J.P.; Slifer, K.; Wong, D.F.; Budimirovic, D.B.; et al. Fragile X Mental Retardation Protein and metabotropic glutamate receptor subtype 5 in fragile X syndrome. [poster]. Society for Neuroscience Global Connectome, Virtual, 12 January 2021.

44. Johnson, M.H.; Charman, T.; Pickles, A.; Jones, E.J.H. Annual Research Review: Anterior Modifiers in the Emergence of Neurodevelopmental Disorders (AMEND)—A systems neuroscience approach to common developmental disorders. J. Child Psychol. Psychiatry 2021. [CrossRef]

45. Darnell, R.B. The genetic control of stoichiometry underlying autism. Annu. Rev. Neurosci. 2020, 43, 509-533. [CrossRef]

46. Fatemi, S.H.; Folsom, T.D. GABA receptor subunit distribution and FMRP-mGluR 5 signaling abnormalities in the cerebellum of subjects with schizo-phrenia, mood disorders, and autism. Schizophr. Res. 2015, 167, 42-55. [CrossRef] [PubMed]

47. Russell, D. A PET Brain Imaging Study of mGluR $_{5}$ in Subjects with Neuropsychiatric Conditions (FPEB). ClinicalTrials.gov Identifier: NCT00870974 2017. Available online: https:/ / clinicaltrials.gov/ct2/show / NCT00870974 (accessed on 7 March 2021).

48. International Committee of Medical Journal Editors (ICMJE). Recommendations for the Conduct, Reporting, Editing, and Publication of Scholarly Work in Medical Journals. 2019. Available online: http://www.icmje.org/icmje-recommendations.pdf (accessed on 7 March 2021).

49. World Medical Association. Declaration of Helsinki: Medical Research Involving Human Subjects. 2013. Available online: https:/ / www.wma.net/what-we-do/medical-ethics/declaration-of-helsinki/ (accessed on 7 March 2021). 
50. Lord, C.; Rutter, M.; Le Couteur, A. Autism Diagnostic Interview-Revised: A revised version of a diagnostic interview for caregivers of individuals with possible pervasive developmental disorders. J Autism Dev. Disord. 1994, 24, 659-685. [CrossRef]

51. Lord, C.; Rutter, M.; Goode, S.; Heemsbergen, J.; Jordan, H.; Mawhood, L.; Schopler, E. Autism Diagnostic Observation Schedule: A standardized observation of communicative and social behavior. J. Autism Dev. Disord. 1989, 19, 185-212. [CrossRef]

52. Brix, G.; Zaers, J.; Adam, L.-E.; Bellemann, M.E.; Ostertag, H.; Trojan, H.; Haberkorn, U.; Doll, J.; Oberdorfer, F.; Lorenz, W.J. Performance evaluation of a whole-body PET scanner using the NEMA protocol. J. Nucl. Med. 1997, 38, 1614-1623.

53. de Jong, H.W.A.M.; van Velden, F.H.P.; Kloet, R.W.; Buijs, F.L.; Boellaard, R.; Lammertsma, A.A. Performance evaluation of the ECAT HRRT: An LSO-LYSO double layer high resolution, high sensitivity scanner. Phys. Med. Biol. 2005, 52, $1505-1526$.

54. Sullivan, J.M.; Lim, K.; Labaree, D.; Lin, S.-F.; McCarthy, T.J.; Seibyl, J.P.; Tamagnan, G.; Huang, Y.; Carson, R.E.; Ding, Y.-S.; et al. Kinetic analysis of the metabotropic glutamate subtype 5 tracer $\left[{ }^{18} \mathrm{~F}\right] \mathrm{FPEB}$ in bolus and bolus plus-constant-infusion studies in humans. J. Cereb. Blood Flow Metab. 2013, 33, 532-541. [CrossRef]

55. Logan, J.; Alexoff, D.; Fowler, J.S. The use of alternative forms of graphical analysis to balance bias and precision in PET images. J. Cereb. Blood Flow Metab. 2011, 31, 535-546. [CrossRef] [PubMed]

56. Budimirovic, D.B.; Bukelis, I.; Cox, C.; Gray, R.M.; Tierney, E.; Kaufman, W.E. Autism spectrum disorder in fragile X syndrome: Differential contribution of adaptive socialization and social withdrawal. Am. J. Med. Genet. Part A 2006, 140A, $1814-1826$. 